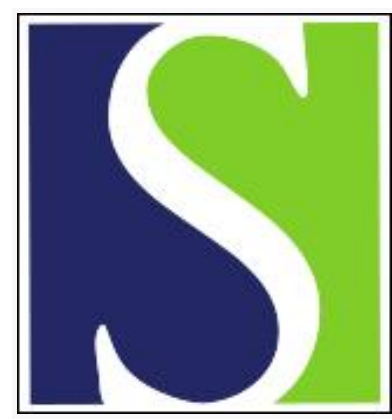

Scand J Work Environ Health 2016;42(6):500-509

https://doi.org/10.5271/sjweh.3590

Published online: 31 Aug 2016, Issue date: 01 Jun 2016

The effect of motherhood and work on women's time pressure: A cohort analysis using the Australian Longitudinal Study on Women's Health

by Otterbach S, Tavener M, Forder P, Powers J, Loxton D, Byles J

This is the first study using the Australian Longitudinal Study on Women's Health to identify time stress in younger Australian women over a 17-year period with a focus on motherhood and work. Understanding the sources of time stress is important if policy-makers want to design and successfully implement health policies, and family-friendly parental leave and childcare policies.

Affiliation: Institute for Health Care \& Public Management, University of Hohenheim, Fruwirthstraße 48, D-70599 Stuttgart, Germany. steffen.otterbach@uni-hohenheim.de

Key terms: Australia; Australian Longitudinal Study on Women's Health; cohort analysis; motherhood; time pressure; time stress; work; working women

This article in PubMed: www.ncbi.nlm.nih.gov/pubmed/27580244 


\title{
The effect of motherhood and work on women's time pressure: A cohort analysis using the Australian Longitudinal Study on Women's Health
}

\author{
by Steffen Otterbach, PhD, ${ }^{1}$ Meredith Tavener, PhD, ${ }^{2}$ Peta Forder, MSc, ${ }^{2}$ Jennifer Powers, MSc, ${ }^{2}$ Deborah \\ Loxton, PhD, ${ }^{2}$ Julie Byles, $P h D^{2}$
}

\begin{abstract}
Otterbach S, Tavener M, Forder P, Powers J, Loxton D, Byles J. The effect of motherhood and work on women's time pressure: A cohort analysis using the Australian Longitudinal Study on Women's Health. Scand J Work Environ Health. 2016;42(6):500-509. doi:10.5271/sjweh.3590
\end{abstract}

\begin{abstract}
Objectives The aim of this study was to analyze the prevalence and determinants of time pressure among younger Australian women born between 1973 and 1978 over a 17-year period.

Methods Using six surveys ( $\mathrm{N}=14247$ at baseline in 1996) from the Australian Longitudinal Study on Women's Health (ALSWH), we estimated fixed-effects ordered logistic regression models.

Results More than two thirds of women felt rushed, pressured, too busy every day or a few times a week, and time pressure substantially increased over the observed 17-year period. Baseline estimates show that time pressure is significantly $(\mathrm{P}<0.001)$ associated with being employed and being a mother with coefficients ranging from 0.255 [ $95 \%$ confidence interval $(95 \% \mathrm{CI}) 0.188-0.322]$ for being employed to $0.273(95 \% \mathrm{CI} 0.168-0.377)$ for having children. The multivariate analysis further indicates that time pressure is significantly related to a number of personal, family, and work characteristics such as number and age of children, economic insecurity such as having financial difficulties, concern about employment stability, or the length of the working week.
\end{abstract}

Conclusions Understanding the sources of time pressure and identification of certain groups which are particularly vulnerable to it is important if policy-makers aim to design and successfully implement health policies, and family-friendly parental leave and child-care policies.

Key terms Australia; cohort study; time pressure; time stress; working women.

Not only does time pressure and not having enough discretionary time appear to be widespread in western societies, but there is also evidence that the phenomenon has become more prevalent in recent decades $(1,2)$. Time is considered a paramount dimension of well-being and overall life satisfaction $(1,3)$. Perceptions of time pressure can result in feeling stressed and can be associated with adverse consequences for physical as well as mental health and well-being including distress, depression, sleep disorder, accelerated ageing or increased risk of diabetes (4-6). The amount of perceived available time capacity also influences life-style including diet, eating habits, and physical activity (7). It therefore may have important public health implications. Given the relationships between time pressure and health, time pressure may be seen as an important factor in increasing health risks at different life stages. However little is known about what factors influence time pressure. The terminology around time pressure is inconsistent as it is also referred to as time stress, time crunch, time squeeze, or time deprivation. In his review of the mixed terminology, Szollos (5) proposes to use the term chronic time pressure of which time shortage and the feeling of being rushed are objective and subjective components, respectively. In our study, we will primarily use the term time pressure.

In the tradition of Becker's prominent and influential Theory of the Allocation of Time (8), Hamermesh and Lee (10) derive an economic theory of what they refer to as time stress. In their unitary model, the authors predict how the "shadow price" (ie, the monetary value assigned to unknowable costs) of time is determined, and the Lagrangean multipliers of the time and goods constraint are used as proxy measures of time stress and financial

1 Institute for Health Care \& Public Management, University of Hohenheim, Stuttgart, Germany.

2 Research Centre for Generational Health and Ageing, University of Newcastle, Callaghan, Australia.

Correspondence to: Steffen Otterbach, Institute for Health Care \& Public Management, University of Hohenheim, Fruwirthstraße 48, D-70599 Stuttgart, Germany, [E-mail: steffen.otterbach@uni-hohenheim.de] 
stress, respectively. This theory predicts that for a given time allocation in which a husband's work hours are held constant, higher wages or additional unearned income will tighten the time constraint.

Following Grossman's (11) theory of health capital, the authors also mention the importance of health as a decisive resource of household production affecting the productivity of time. Therefore, and because health is correlated with other factors such as work hours, it is essential to account for health differences when estimating these models. In addition, increase in efficiency - such as change in household production technology affecting household productivity - is predicted to increase effective time and reduce time stress. Buddelmeyer et al (12) enhance this theoretical framework with a specific focus on how the birth of a child affects time and financial stress. Their estimates show that the birth of a child not only significantly increases the perceived time stress of both husbands and wives but the effect on mothers' time stress is three times as large as that of their husbands'.

Interestingly and in contradiction to the above mentioned theories, Rosa (2) states that technological acceleration, such as more efficient and faster transportation, communication and production processes, induces an acceleration of social change that in turn drives a rapid and permanent change of individuals' environment even in periods in which they have full control over their free time resources. This causes individuals to be constantly delayed or behind, which the author compares to a slippery slope where individuals constantly rush to adjust to their environment and catch up. From the sociotheoretical perspective, another origin of the perception of time pressure lies in the fear of missing out on options, which causes individuals' desire of increasing the rate of experience to realize a fulfilled and eventful life. As a consequence of finite time resources, individuals accelerate their pace of life by increasing the number of episodes of action per time unit.

Demands upon a person's time are expected to vary throughout the course of life, such as those age brackets when people are most likely to marry, become parents and care for children (13). From a life-course perspective, parents with young children are especially prone to feeling time pressured. Compared to other adults, parents have the least free time, spend less time sleeping and doing personal care activities and are the most likely to report being often rushed or pressed for time (14). Parental time pressure can be associated with depression (15) and act as a barrier to parents in making healthy lifestyle choices for their children (16). Internationally, as well as in Australia, research has shown that parents in households with children experience greater time pressure than those without children (17). While both parenting and work responsibilities may differ from person to person, women's time pressure in particular is affected by the presence of young children $(18,19)$. Despite gender-equal family and labor market policies, women continue to bear the major share of household work, are the main caregivers to their children and other family members, and have less time for leisure (20).

In addition, women's increasing labor market participation documented for most OECD countries over the past decades can impose the burden of multiple work obligations and family responsibilities including child rearing and caregiving $(21,22)$. In the United States, more women among married couples reported feeling always rushed or pressured for time, when both were working ( $26 \%$ of women versus $19 \%$ of men) (10), although greater earnings could also be associated with greater time pressure even when hours worked remain constant. Among the four Scandinavian countries (Denmark, Finland, Norway, Sweden) known as societies with gender-equal family policies, $14.2 \%(11.6 \%)$ of working mothers (fathers) reported time pressure "most often" (23). Women in dual-income families in Canada continue to undertake $>60 \%$ of household chores and report feeling "extremely" time pressured as a result (24).

Based on the reviewed theoretical and empirical literature, it was hypothesized that the sources of time pressure stem from the competing burdens of employment, child rearing, and household responsibilities. Specifically, we hypothesized that (i) having one or more children, (ii) the number of children, (iii) having younger children, and (iv) being in paid work influence women's time pressure. Moreover, it was also hypothesized that (v) time pressure was increased when (maternal) employment was combined with long work hours, having financial difficulties, job insecurity, and being over- or underemployed. These hypotheses were operationalized and tested in a national cohort study among participating women from the 197378 birth cohort of the Australian Longitudinal Study on Women's Health (ALSWH), using data from six consecutive surveys over a 17-year time period. To account for the longitudinal feature of the data and the categorical nature of our dependent variable time pressure, we estimated fixed-effects ordered logit models using a new estimator by Baetschmann et al (25) which enabled us to control for unobserved heterogeneity potentially being related to the perception of time pressure.

\section{Methods}

\section{Data source}

The ALSWH is a large national cohort study which provides representative data on factors which affect the health of women, and their use of health services (www. 
alswh.org.au). Recruitment of the cohort utilized the national Medicare health database as a sampling frame (26). This study analyzed data provided by women from the 1973-1978 birth cohort, initially recruited by mailed survey in 1996. The women were surveyed in 1996 (aged 18-23 years with 14247 respondents), with subsequent surveys in 2000, 2003, 2006, 2009, and 2012 (aged 34-39 years, 8126 respondents). After a drop in the response rate between surveys 1 and 2 (with 9688 respondents in 2000), responses were 9081, 9145, 8200, and 8126 in 2003, 2006, 2009, and 2012 respectively (26). By 2012, 92 participants were deceased or disabled and 1157 had withdrawn from the study. Participants who missed one wave were contacted at subsequent waves resulting in $>80 \%$ responding at subsequent surveys $(27,28)$. Participants provided informed consent and the Human Research Ethics Committees of the Universities of Newcastle and Queensland approved the study (29).

\section{Measures}

Main outcome variable. For this paper, the main outcome variable is time pressure, measured at every survey. Time pressure refers to women's responses to the survey question "How often do you feel that you are rushed, pressured, too busy?" Five response categories were provided: "Every day", "A few times a week", "About once a week", "About once a month", and "Never".

Main explanatory variables. Motherhood was defined as having $\geq 1$ child(ren) ("yes" or "no"), as well as the number of children $(0,1,2,3, \geq 4)$. In addition, categories for the age of the youngest child $(<1,1-<3,3-<5,5-<12$, $\geq 12$ years) were created based on children's date of birth, which was used in analyses restricted to mothers only.

In the first instance, work status was defined as being in paid work ("yes" or "no"). To account for the potential interaction of work and motherhood, a variable was derived for the combination of being in paid work ("yes"/"no") and having children ("yes"/"no"). For additional analyses, we also included the length of the work week to analyze the impact on time pressure when employment was combined with other demanding conditions such as long work hours. Respondents were asked to state the number of work hours in a usual work week using six hour categories: $1-15,16-24,25-34,35-40$, $41-48, \geq 49$ hours.

Other explanatory variables. Civil status ("partnered" or "not partnered"), self-rated health ("excellent", "very good", "good", "fair", "poor"), and residential area ("rural and remote area" or "urban") were measured at all surveys. Provision of unpaid care or assistance to another person was determined when respondents indicated if they regularly provided care to other persons due to long-term illness, disability or frailty ("yes"/"no"). Financial stress was determined by the response given when participants indicated their ability to manage on their available income ("impossible/difficult all the time" versus "difficult some of the time/not too bad/easy"). For women who indicated being in paid work, specific work characteristics included job insecurity ("sometimes/all the time worried about losing the job" or "rarely or never worried about losing the job"); being underemployed ("would like to work more" or "happy as is"); being overemployed ("would like to work less" or "happy as is").

The above listed variables were collected at all six surveys, with the exception of job insecurity and underand overemployment, which were collected from survey 3 onwards.

\section{Statistical analyses}

Due to the ordinal categorical feature of the dependent variable, we estimated parameters from fixed-effects ordered logit models, applying a new estimator as proposed by Baetschmann et al (25), using Stata code provided by Baetschmann, Staub and Winkelmann (30). The "blow up and cluster" (BUC) estimator, using restricted conditional maximum likelihood methods, has been demonstrated to outperform existing fixed-effect estimators for similar models, particularly if the ordered dependent variable exhibits low frequencies in certain categories. Existing estimators are based on the idea to simplify the estimation problem by dichotomizing the ordered response category into a binary variable and implementing a fixed-effects binary logit model. The decisive difference between these estimators is the way the cut-off point for dichotomization is defined. The BUC estimator estimates all possible dichotomizations jointly, essentially replacing every observation in the sample by $\mathrm{K}-1$ copies of itself ("blowing up" the sample size), and dichotomizing each of the $\mathrm{K}-1$ copies of the individual at a different cut-off point. Conditional maximum likelihood methods are used on the entire sample to obtain the BUC estimates, while the standard errors are clustered at the individual level.

\section{Results}

Descriptive characteristics of the women at surveys 1 and 6 are presented in table 1 .

\section{Prevalence of time pressure}

In $1996,17.9 \%$ of younger Australian women aged 18-23 years old reported feeling rushed, pressured or 
Table 1. Descriptive characteristics of the 1973-1978 birth cohort from the Australian Longitudinal Study on Women's Health, at surveys 1 and 6 . [SD=standard deviation]

\begin{tabular}{|c|c|c|c|c|}
\hline & \multicolumn{2}{|c|}{$\begin{array}{l}\text { At survey } 1 \\
(1996) \\
(\mathrm{N}=14247)\end{array}$} & \multicolumn{2}{|c|}{$\begin{array}{c}\text { At survey } 6 \\
(2012) \\
(\mathrm{N}=8126)\end{array}$} \\
\hline & Mean & SD & Mean & SD \\
\hline Partnered & 0.22 & 0.42 & 0.78 & 0.42 \\
\hline Having $\geq 1$ child(ren) & 0.06 & 0.24 & 0.74 & 0.44 \\
\hline Number of children & 0.08 & 0.33 & 1.61 & 1.24 \\
\hline Age of youngest child (years) & 1.44 & 1.19 & 4.73 & 3.86 \\
\hline Health satisfaction $(1-5)^{\text {a }}$ & 2.50 & 0.89 & 2.37 & 0.88 \\
\hline Working & 0.39 & 0.49 & 0.80 & 0.40 \\
\hline Working $\times$ having (a) child(ren) & 0.01 & 0.11 & 0.57 & 0.50 \\
\hline \multicolumn{5}{|l|}{ Work hours/week b } \\
\hline $1-15$ & 0.12 & 0.33 & 0.16 & 0.36 \\
\hline $16-24$ & 0.12 & 0.32 & 0.19 & 0.39 \\
\hline $25-34$ & 0.12 & 0.33 & 0.16 & 0.36 \\
\hline $35-40$ & 0.41 & 0.49 & 0.23 & 0.42 \\
\hline $41-48$ & 0.18 & 0.38 & 0.14 & 0.35 \\
\hline$\geq 49$ & 0.05 & 0.23 & 0.12 & 0.33 \\
\hline Provide care & 0.07 & 0.26 & 0.09 & 0.28 \\
\hline Living in rural/remote area (ref.=urban) & 0.45 & 0.50 & 0.40 & 0.49 \\
\hline Financial difficulties & 0.18 & 0.39 & 0.13 & 0.34 \\
\hline Job insecurity b, c & . & & 0.20 & 0.40 \\
\hline Underemployed ${ }^{b, c}$ & . & & 0.11 & 0.31 \\
\hline Overemployed b, c & . & & 0.25 & 0.43 \\
\hline
\end{tabular}

too busy every day. When aged 34-39 years old in $2012,29.8 \%$ of the same cohort of women reported feeling time pressured every day. Figure 1 compares the prevalence of time pressure among women with and without children, suggesting that motherhood could be associated with higher levels of time pressure. In 1996 , $23.8 \%$ women with children reported feeling pressured, rushed, busy every day increasing to $33 \%$ of women with children in 2012 . In contrast, only $17.3 \%$ of women without children reporting feeling pressured, rushed, busy in 1996 increasing slightly to $20.5 \%$ of women without children in 2012 .

\section{Determinants of time pressure}

In our specific focus on motherhood and work, our initial analyses aimed at evaluating the impact on women's time pressure of having $\geq 1$ child(ren), the number of children, having younger children, and being in paid work. We included a number of variables which were available across all 6 surveys (see table 2). Models 1 and 2 included all women in our sample and showed that time pressure is more prominent among women with children (model 1) and increases with the number of children (model 2). Being in paid work was also associated with higher levels of time pressure. Both models

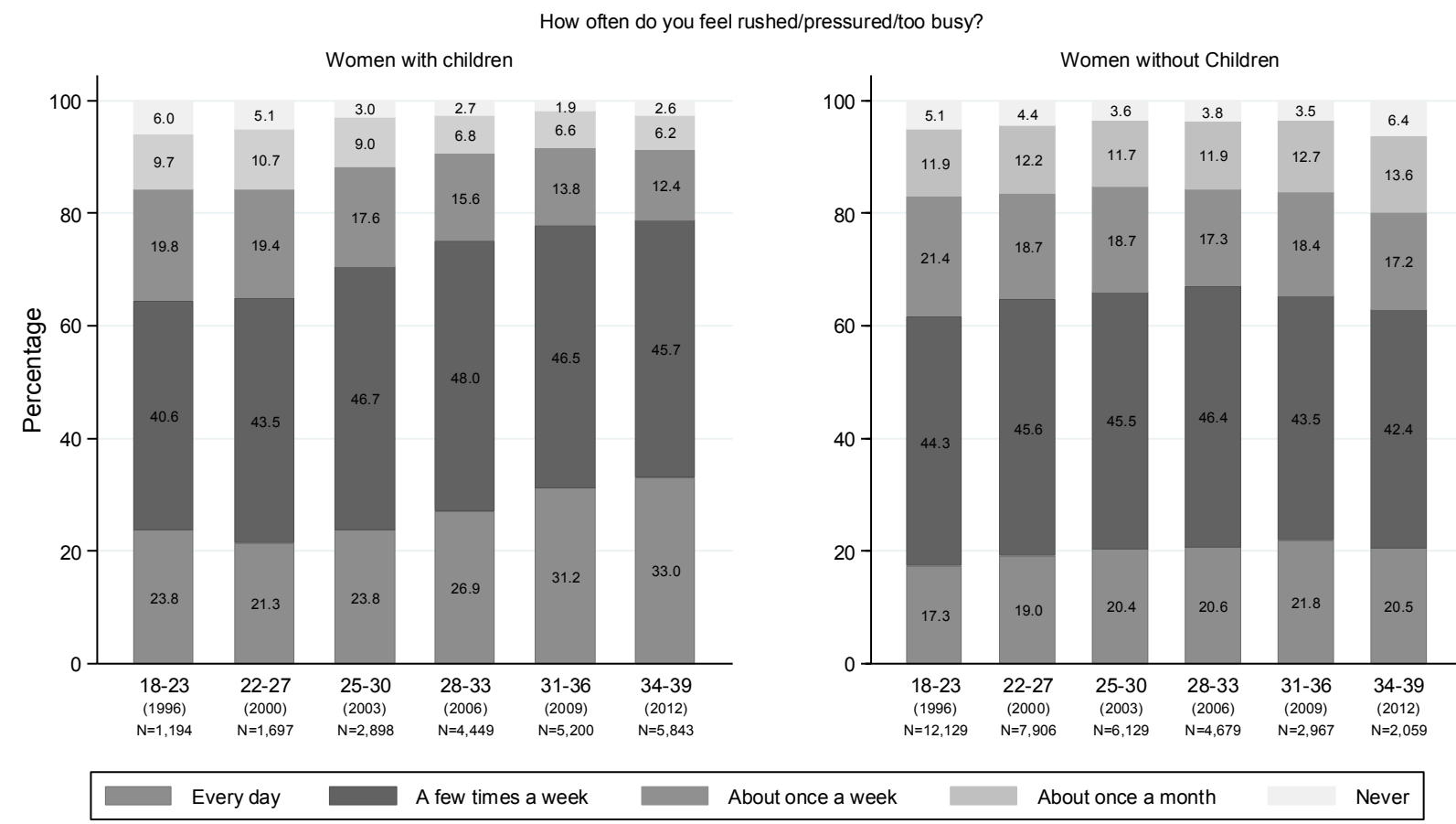

Data: Australian Longitudinal Survey on Women's Health, participants from the 1973-78 birth cohort, surveyed approximately every 3 years

Figure 1. Prevalence of time pressure among younger Australian women (with/without children), between 1996 and 2012. 
additionally include an interaction term between having children and being in paid work, which significantly compounds time pressure, ie, time pressure associated with being a mother is aggravated if working. Moreover, having poorer health and providing care to other persons were also related to higher levels of time pressure. Interestingly, having a partner and living in rural/remote areas show no significant relation to time pressure.

Model 3 additionally includes age categories of the youngest child. As an important insight from this specification, we find that the size of the coefficients for the age categories increases as the age of the youngest child increases up to age category $5-<12$ (ie, primary school age when children participating in extra-curricular activities have limited ability to manage their activities including transport to/from school independently), and then slightly decreases if the youngest child is $\geq 12$ years (ie, high school age when children become more independent and capable of self-managing activities).

We extended our regression models (see table 3 ) to analyze whether time pressure is associated with other tight personal and work conditions such as long work hours, job insecurity, under- or overemployment, and whether a respondent has financial difficulties or not. We classified weekly workload using work hours categories with low work hours (1-15 hours) being the reference category. As these variables were not available across all surveys and work characteristics can only be observed for employed respondents, this analysis is limited to surveys 3 to 6 and to a subsample of working women (model 4) and working mothers (models 5 and 6). Similar to the results in table 2 , having children, the number of children, poorer self-rated health, and providing care significantly increase the likelihood of time pressure.

Increasing work hours were significantly associated with increased time pressure among working women. In addition to this work hour effect, being overemployed in the sense that a respondent would like to work less (regardless of actual work hours) is associated with higher levels of time pressure whereas underemployment is related to lower levels of time pressure. Having financial difficulties and job insecurity also significantly increase time pressure. Similar to the results presented in model 3, model 6 shows that the likelihood of time pressure increases as the age of the youngest child reaches school age $(5-<12)$, although there was no evidence of an association when the youngest child was older (aged $\geq 12$ years).

\section{Discussion}

Reasons behind the perception of being rushed, pressured and pushed for time are likely complex, with women balancing time as a parent, paid worker, partner, home-maker and caregiver, among others (31). Our analysis of survey data for a large population-based sample of younger Australian women over a 17-year period revealed that being a parent and participating in paid

Table 2. Fixed-effects ordered logit estimates of the association of motherhood and working on time pressure among Australian women over a 17-year period (1996-2012). Data from the Australian Longitudinal Survey on Women's Health, participants from the 1973-1978 birth cohort. The dependent variable is time pressure measured on an ordinal 5-point scale. Models (1) and (2) include all women. Model (3) includes women with children. Survey/time indicators included as control variables (not reported here) $[$ Coef=coefficient; $95 \% \mathrm{Cl}=95 \%$ confidence interval].

\begin{tabular}{|c|c|c|c|c|c|c|}
\hline \multirow[t]{2}{*}{ Independent variables } & \multicolumn{2}{|c|}{ Model (1) } & \multicolumn{2}{|c|}{ Model (2) } & \multicolumn{2}{|c|}{ Model (3) } \\
\hline & Coef & $95 \% \mathrm{Cl}$ & Coef & $95 \% \mathrm{Cl}$ & Coef & $95 \% \mathrm{Cl}$ \\
\hline Partnered & -0.043 & $0.098-0.013$ & -0.027 & $-0.082-0.029$ & 0.036 & $-0.116-0.187$ \\
\hline Having $\geq 1$ child(ren) & $0.273^{a}$ & $0.168-0.377$ & & & & \\
\hline Number of children & & & 0.420 a & $0.377-0.464$ & $0.728^{\text {a }}$ & $0.620-0.836$ \\
\hline Health satisfaction & 0.221 a & $0.190-0.253$ & 0.219 a & $0.188-0.250$ & 0.221 a & $0.158-0.285$ \\
\hline Working & $0.255^{a}$ & $0.188-0.322$ & 0.414 a & $0.355-0.473$ & 0.616 a & $0.512-0.720$ \\
\hline Working $\times$ having $(\mathrm{a})$ child(ren) & $0.326^{a}$ & $0.226-0.425$ & 0.082 b & $0.002-0.162$ & & \\
\hline Provide care & $0.253^{a}$ & $0.161-0.346$ & $0.242^{a}$ & $0.149-0.335$ & $0.218^{b}$ & $0.046-0.389$ \\
\hline Living in rural/remote area (ref.=urban) & -0.004 & $-0.079-0.071$ & -0.039 & $-0.114-0.036$ & 0.065 & $-0.124-0.254$ \\
\hline \multicolumn{7}{|l|}{ Age of youngest child [years] (ref.: $<1$ ) } \\
\hline $1-<3$ & & & & & $0.155^{c}$ & $0.044-0.265$ \\
\hline $3-<5$ & & & & & $0.231^{a}$ & $0.100-0.362$ \\
\hline $5-<12$ & & & & & 0.439 a & $0.255-0.623$ \\
\hline$\geq 12$ & & & & & 0.348 & $-0.020-0.716$ \\
\hline Number of observations & 97634 & & 97634 & & 24025 & \\
\hline Number of clusters/persons & 10629 & & 10629 & & 4364 & \\
\hline Log pseudo-likelihood & -35929 & & -35561 & & -8126 & \\
\hline
\end{tabular}


Table 3. Fixed-effects ordered logit estimates of the association of motherhood and employment factors on time pressure among working Australian women over a 10-year period (2003-2012). Data from the Australian Longitudinal Survey on Women's Health, participants from the 1973-1978 birth cohort. The dependent variable is time pressure measured on an ordinal 5-point scale. Models (1) and (2) include all women. Model (3) includes women with children. Survey/time indicators included as control variables (not reported here) [Coef=coefficient; $95 \% \mathrm{Cl}=95 \%$ confidence interval].

\begin{tabular}{|c|c|c|c|c|c|c|}
\hline \multirow[t]{2}{*}{ Independent variables } & \multicolumn{2}{|c|}{ Model (4) } & \multicolumn{2}{|c|}{ Model (5) } & \multicolumn{2}{|c|}{ Model (6) } \\
\hline & Coef & $95 \% \mathrm{Cl}$ & Coef & $95 \% \mathrm{Cl}$ & Coef & $95 \% \mathrm{Cl}$ \\
\hline Partnered & -0.005 & $-0.112-0.102$ & -0.006 & $-0.270-0.257$ & 0.093 & $-0.173-0.359$ \\
\hline Having $\geq 1$ child(ren) & $0.983^{a}$ & $0.842-1.125$ & & & & \\
\hline Number of children & & & 0.938 a & $0.792-1.083$ & $1.009 \mathrm{a}$ & $0.832-1.185$ \\
\hline Health satisfaction & 0.199 a & $0.144-0.254$ & $0.211^{\text {a }}$ & $0.110-0.313$ & $0.200^{a}$ & $0.099-0.301$ \\
\hline Provide care & $0.388^{\text {a }}$ & $0.226-0.550$ & $0.337^{b}$ & $0.092-0.582$ & $0.326^{a}$ & $0.079-0.572$ \\
\hline Living in rural/remote area (ref.=urban) & 0.011 & $-0.139-0.161$ & -0.074 & $-0.409-0.261$ & -0.128 & $-0.462-0.206$ \\
\hline \multicolumn{7}{|l|}{ Work hours/week (ref. $=1-15$ ) } \\
\hline $16-24$ & $0.393^{a}$ & $0.264-0.522$ & $0.540^{\text {a }}$ & $0.362-0.719$ & $0.503^{a}$ & $0.323-0.682$ \\
\hline $25-34$ & $0.424^{\text {a }}$ & $0.281-0.567$ & $0.701^{\text {a }}$ & $0.486-0.917$ & $0.631^{\mathrm{a}}$ & $0.414-0.848$ \\
\hline $35-40$ & $0.493^{\text {a }}$ & $0.352-0.635$ & $0.802^{\text {a }}$ & $0.570-1.034$ & $0.730^{\mathrm{a}}$ & $0.500-0.960$ \\
\hline $41-48$ & $0.913^{\text {a }}$ & $0.758-1.068$ & 1.028 a & $0.730-1.327$ & $0.967^{\text {a }}$ & $0.670-1.263$ \\
\hline$\geq 49$ & $1.177^{\mathrm{a}}$ & $1.002-1.352$ & 1.199 a & $0.909-1.489$ & $1.163^{a}$ & $0.871-1.455$ \\
\hline Financial difficulties & 0.405 a & $0.268-0.542$ & $0.337^{b}$ & $0.117-0.557$ & $0.335^{a}$ & $0.115-0.556$ \\
\hline Job insecurity & $0.340^{\mathrm{a}}$ & $0.239-0.442$ & $0.423^{\text {a }}$ & $0.237-0.610$ & $0.420^{\mathrm{a}}$ & $0.234-0.607$ \\
\hline Underemployed & $-0.356^{a}$ & $-0.488--0.225$ & $-0.229^{c}$ & $-0.439--0.020$ & $-0.256^{c}$ & $-0.468--0.043$ \\
\hline Overemployed & $0.931^{a}$ & $0.837-1.026$ & $0.836^{a}$ & $0.664-1.007$ & $0.835^{a}$ & $0.663-1.007$ \\
\hline \multicolumn{7}{|l|}{ Age of youngest child [years] $($ ref.: $<1)$} \\
\hline $1-<3$ & & & & & $0.324^{\mathrm{a}}$ & $0.127-0.521$ \\
\hline $3-<5$ & & & & & $0.482^{a}$ & $0.266-0.699$ \\
\hline $5-<12$ & & & & & $0.637^{a}$ & $0.343-0.931$ \\
\hline$\geq 12$ & & & & & 0.369 & $-0.176-0.915$ \\
\hline Number of observations & 29131 & & 9414 & & 9414 & \\
\hline Number of clusters/persons & 5972 & & 2442 & & 2442 & \\
\hline Log pseudo-likelihood & -9694 & & -2994 & & -2969 & \\
\hline
\end{tabular}

employment increased women's perceptions of being rushed, pressured and pushed for time. As with previous studies $(19,23)$ we found that time pressure increased as the number of children and work hours increased.

Opposing theoretical approaches to work and family posit that women's time pressure would be reduced if they concentrated on home and child care without adding competing demands from work outside the home (32), but also that potential benefits exist for women who manage various roles in their lives (33). While for some women it might be favorable to reduce work hours, part-time employment is generally associated with lower earnings and benefits (21). Our analysis showed higher levels of time pressure among women with children, who were also employed, indicative of the double burden when work and family obligations simultaneously occur and women have to fulfill the both roles of being a mother and an income earner. Taking the role as a caregiver and providing unpaid care or assistance for persons in need also reduces the time resources available and increases women's time pressure - a finding which is not only plausible but also reported by Hamermesh and Lee (10) for Germany and Australia.

Surprisingly, having a partner does not exhibit any impact on women's time pressure. In principle, we would expect that having a partner contributing at least to some extent to household chores and household income would loosen the time constraint and reduce time pressure. Moreover, adequate parental investments in children in terms of time and money become more feasible if children are raised together with a partner (34), and therefore having a partner would be assumed to reduce time pressure. However, numerous studies confirm the gendered division of housework and childcare responsibilities with women still bearing the major share of household chores and acting as the primary caregivers $(20,24,35)$. Moreover, such "gender roles" are more pronounced among partnered women, whereas single women and single mothers are less likely to participate in "gender activities" (36). Thus, the insignificance of having a partner or not could be a reflection of that gender disparity if partnered women are exposed to higher time pressure due to their gender roles (36) and single women instead have higher time pressure due to the lack of a partner's contribution.

How people spend their time matters for quality of life. Among mothers who also participate in paid employment, nearly half can feel they spend too little time with their children (37). In 2008, 63\% of Australian women with dependent children were in paid employ- 
ment, with $60 \%$ employed part time (38), perhaps as a strategy to reconcile competing demands on their time from having to work and manage family life (39). A survey of social attitudes in Australia found that over $70 \%$ of people would like to spend more time in leisure pursuits or with family, and almost $40 \%$ wanted to spend less time at work. Although the debate continues as to whether part-time employment actually reduces time pressure for mothers (40), our study found that time pressure associated with being a mother was aggravated when the woman was in paid employment. Increasing work hours was significantly associated with increased time pressure, and being overemployed in the sense that a woman would like to work less (regardless of actual work hours) was associated with higher levels of time pressure whereas underemployment was related to lower levels of time pressure.

In contrast to existing research reporting that more wealthy individuals are exposed to higher levels of time pressure $(10,41)$, we found that women who experience greater difficulty managing on their available income also report significantly higher time pressure - a finding which is also consistent with the results reported by Gunnarsdottir et al (23). Higher income individuals and/ or families can work very long hours. A higher education level is usually associated with higher paid employment. However, mothers with a high education level can experience greater time pressure than those with less education (42), perhaps signifying the woman's efforts to maximize her perceived commitments to both family and employer (43). A report on growing up in Australia showed that $18 \%$ of mothers who worked 1-15 hours/ week felt they missed out on family activities, compared to $57 \%$ of mothers who worked full time (44). Further, women's feelings of missing out and being rushed for time did not abate as the child(ren) grew older.

If time is considered a health resource in itself, then the experience of time pressure for mothers could result in limited opportunities to access health services, prepare healthy food, play with their children and exercise - all of which are essential to good health (45). Our finding that poorer self-rated health was associated with increased time pressure is consistent with findings by Hamermesh and Lee (10). Work by Floderus et al (46) looking at $>5000$ Swedish women revealed that mothers perceived their health as poor more often than women without children. This association was also stronger among younger (20-29 years) compared to older (30-43 years) women.

"Family friendly" policies are instigated with a view to helping alleviate work-life tensions and supporting individuals in managing multiple responsibilities. Entitlements can include flexible start and finish times at work, carers' leave, job sharing, part time work, informal arrangements and parental leave (47). How- ever, the availability of such initiatives is not uniform across work sectors, organizations, time in the job and level of seniority. However, results from our study help policy-makers identify a key "leverage point" in terms of ages of children when mothers experience greater time pressure and could benefit from interventions that aim to help them manage on a daily basis. Our data demonstrates that time pressure increases as children age until they are about 12 years. When children reach this age, they become more independent and require less handson-care, an important turning point that is also consistent with Gunnarsdottir et al (23) who found that mothers of pre- and primary-school children were more likely to feel time pressure compared to mothers of children $>13$ years. This finding could be a direct reflection of children being able to take on more responsibility for their activities, self-management of transport, and care for themselves more independently, and thus release mothers' time resources and attenuate time pressure.

\section{Method discussion}

We analyzed time pressure among women born between 1973 and 1978 and followed these women from the age of 18-23 over 17 years until the age of 34-39 years. The longitudinal feature of our data enabled us to address the question of how time pressure evolves over a time in women's lives when most begin working, get married, and start a family. In contrast to existing cross-sectional studies, we were able to examine the determinants of time pressure exempt from the influence of cohort effects.

A number of previous studies simplified the estimation problem with the ordinal categorical dependent variable "time pressure" by a dichotomization into a binary variable, defining being pressured for time as feeling rushed "most often", "almost always" or "often" $(10,23)$. In our application of the BUC estimator, we were able to account for the original ordinal categorical feature of our dependent variable time pressure measured on a 5-point scale. The longitudinal nature of our data enabled us to control for time-invariant unobserved factors, which is of particular importance when outcomes and exposures are based on self-reports (48).

In this present study, several variables including time pressure, self-assessed health, and job (in)security were based on subjective self-reported data and could therefore be influenced by unobserved personal factors such as personality, motivation, positive or negative affectivity, extrovertism, resilience, or hardiness (49). Using fixed-effects ordered logit models, we were able to hold the influences of these unobserved third factors constant and control for unobserved heterogeneity.

A limitation of our study could be that, due to data limitations, we used a single-item measure of time pressure. Most particularly, from a psychologi- 
cal perspective (50) it could be argued that multi-item measures such as in Roxburgh (4) and Garhammer (1) would better capture multidimensional aspects of time pressure. However, our study was able to measure time pressure in a representative sample of contemporary women. A strength which other studies have been unable to address. The validation of the singleitem measure of time pressure used in our and other cited studies $(10,12,23)$ and a direct comparison to a multi-item measure could be an interesting avenue for further research.

The scope of this research excluded investigating cultural factors that may have added to women's perceptions of being rushed and pressured for time, as well as women's beliefs of what activities others feel they should be doing that result in insufficient or "quality", free time. Moreover, we do not have information about the conditions under which women are employed. Though we condition on a rich set of explanatory variables, there may be other factors such as work time arrangements or commuting time associated with time pressure that are due to data limitations and for which we are unable to control. Nor can we separate time pressure experienced at work versus at home. Another potential limitation to the current research is the response rate of the ALSWH participants, particularly the drop in respondents from survey 1 to survey 2. Despite this decrease, the ALSWH data from this cohort have been shown to provide reliable associations between variables (27).

\section{Concluding remarks}

This study offered valuable insights of how time pressure is related to managing different and potentially multiple roles such as child rearing, being an income-earner, and a care giver. Given the prevalence of time pressure, the issue of how to balance pressure resulting from different sources and the roles women fulfill becomes an essential social question in modern societies. This question is particularly relevant in the context of changing patterns of labor market participation, economic insecurity, ageing societies, ageing workforces, and the trend of increasing chronic disease.

In terms of public health, understanding the sources of time pressure and identification of certain groups that are particularly vulnerable to time pressure is of paramount importance for effective implementation of health policies. Identifying key "leverage points" in a timely manner when mothers need help most to reduce time pressure is particularly important if policy-makers aim to design and successfully implement parental health policies, family-friendly parental leave and child-care policies. Understanding the negative effects of time pressure is also central and is a planned topic for exploration in the future. Moreover, we need to place value on the stress and health impacts of being too rushed and pressured for time and recognize the effect this can have on health and wellbeing.

\section{Human participant protection}

These data were entirely anonymized.

\section{Acknowledgements}

The research on which this paper is based was conducted as part of the University of Newcastle and University of Queensland's Australian Longitudinal Study on Women's Health. We are grateful to the Australian Government Department of Health for funding and to the women who provided the survey data. We would like to thank Alfonso Sousa-Poza for valuable comments and discussion.

\section{References}

1. Garhammer M. Pace of life and enjoyment of life. J Happiness Stud. 2002;3(3):217-56. http://dx.doi. org/10.1023/A:1020676100938.

2. Rosa H. Social Acceleration: A New Theory of Modernity. New York, USA: Columbia University Press; 2013.

3. Gärling T, Krause K, Gamble A, Hartig T. Emotional wellbeing and time pressure. Psych J. 2014;3(2):132-43. http:// dx.doi.org/10.1002/pchj.52.

4. Roxburgh S. „There just aren't enough hours in the day": The mental health consequences of time pressure. J Health Soc Behav. 2004;45(2):115-31. http://dx.doi.org/10.1177/00221 4650404500201 .

5. Szollos A. Toward a psychology of chronic time pressure - Conceptual and methodological review. Time Soc. 2009;18(2/3):332-50. http://dx.doi. org/10.1177/0961463X09337847.

6. Roxburgh S. "I wish we had more time to spend together ..." - The distribution and predictors of perceived family time pressures among married men and women in the paid labor force. J Fam Issues. 2006;27(4):529-53. http://dx.doi. org/10.1177/0192513X05284008.

7. Welch N, McNaughton SA, Hunter W, Hume C, Crawford D. Is the perception of time pressure a barrier to healthy eating and physical activity among women. Public Health Nutr. 2009;12(7):888-95. http://dx.doi.org/10.1017/ S1368980008003066.

8. Becker GS. A theory of the allocation of time. Econ J. 1965;75:491-517. http://dx.doi.org/10.2307/2228949.

9. Gronau R. Home production: A forgotten industry. Rev Econ Stat. 1980;62:408-16. http://dx.doi.org/10.2307/1927108.

10. Hamermesh DS, Lee J. Stressed out on four continents: Time 
crunch or yuppie kvetch? Rev Econ Stat. 2007;89(2):374-83. http://dx.doi.org/10.1162/rest.89.2.374.

11. Grossman M. On the concept of health capital and the demand for health. J Polit Econ. 1972;80:223-55. http://dx.doi. org/10.1086/259880.

12. Buddelmeyer H, Hamermesh DS, Wooden M. The stress cost of children. NBER Working Paper No. 21223; 2015.

13. Moen P, Roehling P. The Career Mystique. Mayland, USA: Rowman \& Littlefield Publishers; 2005.

14. Australian Bureau of Statistics. How Australians Use Their Time. Canberra, ACT, Australia: Australian Bureau of Statistics (ABS); 2006.

15. Roxburgh S. Parental time pressures and depression among married dual-earner parents. J Family Issues. 2012;33(8):102753. http://dx.doi.org/10.1177/0192513X11425324.

16. Stenhammar C, Sarkadi A, Edlund B. The role of parents' educational background in healthy lifestyle practices and attitudes of their 6-year-old children. Publ Health Nutr 2007;10:1305-13. http://dx.doi.org/10.1017/ S1368980007696396.

17. Larsson J. Om föräldrars tidspress - orsaker och förändringsmöjligheter [Parents' time pressure: Causes and opportunities for change]. Research report 139; 2007.

18. Peters $\mathrm{P}$, van der Lippe T. The time-pressure reducing potential of telehomeworking: The Dutch case. Int J Hum Resour Man. 2007;18(3):430-47. http://dx.doi. org/10.1080/09585190601167730.

19. Deding M, Lausten M. Gendered time-crunch and work factors in Denmark. Soc Indic Res 2011;101:249-53. http://dx.doi. org/10.1007/s11205-010-9643-2.

20. Craig 1, Mullan K. Parenthood, gender and work-family time in the united States, Australia, Italy, France, and Denmark. J Marriage Fam. 2010;72:1344-61. http://dx.doi.org/10.1111/ j.1741-3737.2010.00769.x.

21. Blau FD, Kahn LM. Female Labor Supply: Why Is the United States Falling Behind? Am Econ Rev. 2013;103(3):251-6. http://dx.doi.org/10.1257/aer.103.3.251.

22. Jaumotte F. Labour force participation of women: Empirical evidence on the role of policy and other determinants in OECD countries. OECD; 2004. http://dx.doi.org/10.1787/ eco_studies-v2003-art9-en.

23. Gunnarsdottir H, Petzold M, Povlsen L. Time pressure among parents in the Nordic countries: A population-based crosssectional study. Scand J Public Health. 2014;42(2):137-45. http://dx.doi.org/10.1177/1403494813510984.

24. Jackson A. Work and Labour in Canada: Critical Issues. Vol 2nd Ed. Toronto, Canada: Canadian Scholars' Press; 2010.

25. Baetschmann G, Staub KE, Winkelmann R. Consistent estimation of the fixed effects ordered logit model. Journal of the Royal Statistical Society: Series A. 2015;178:685-703. http://dx.doi.org/10.1111/rssa.12090.

26. Dobson AJ, Hockey R, Brown WJ, et al. Cohort Profile Update: Australian Longitudinal Study on Women's Health. Int J Epidemiol. 2015;44(5):1547-1547f. http://dx.doi. org/10.1093/ije/dyv110.
27. Powers J, Loxton D. The Impact of Attrition in an 11-Year Prospective Longitudinal Study of Younger Women. Ann Epidemiol. 2010;20(4):318-21. http://dx.doi.org/10.1016/j. annepidem.2010.01.002.

28. Powers J, Tavener M, Graves A, Loxton D. Loss to followup was used to estimate bias in a longitudinal study: A new approach. J Clin Epidemiol. 2015;68:870-6. http://dx.doi. org/10.1016/j.jclinepi.2015.01.010.

29. Lee C, Dobson AJ, Brown WJ, et al. Cohort profile: The Australian Longitudinal Study on Women's Health. Int J Epidemiol. 2005;34(5):987-91. http://dx.doi.org/10.1093/ije/ dyi098.

30. Baetschmann G, Staub KE, Winkelmann R. Consistent estimation of the fixed effects ordered logit model. Available from: http://ftp.iza.org/dp5443.pdf. [Accessed 9 October 2015]; 2011.

31. Marshall K. Converging gender roles. 2006. Available from: http://statcan.gc.ca/pub/75-001-x/10706/9268-eng.pdf. [Accessed 17 August 2015].

32. Fowlkes MR. Role combinations and role conflict: Introductory perspective. In: Crosby FJ, ed. Spouse, parent, worker: On gender and multiple roles: New Haven, CT: Yale University; 1987.

33. Barnett RC, Hyde JS. Women, men, work, and family: An expansionist theory. Am Psychol. 2001;56:781-96. http:// dx.doi.org/10.1037/0003-066X.56.10.781.

34. Carlson MJ, Berger LM. What kids get from parents: Packages of parental involvement across complex family forms. Soc Serv Rev. 2013;87(2):213-49. http://dx.doi.org/10.1086/671015.

35. Sirianni C, Negrey C. Working time as gendered time. Fem Econ. 2000;6(1):59-76. http://dx.doi. org/10.1080/135457000337679.

36. Zilanawala A. Women's time poverty and family structure. Differences by parenthood and employment. J Fam Issues. 2016;37(3):369-92. http://dx.doi. org/10.1177/0192513X14542432.

37. Bianchi SM, Robinson JP, Milkie MA. Changing Rhythms of American Family Life. New York, USA: Russell Sage Foundation; 2006.

38. Australian Bureau of Statistics. Families week fact and figures from the ABS. Canberra, ACT, Australia: ABS; 2008.

39. Hosking A, Western M. The Effects of Non-standard Employment on Work-Family Conflict. J Sociol. 2008;44(1):527. http://dx.doi.org/10.1177/1440783307085803.

40. Craig L, Mullan K. The Policeman and the Part-time Sales Assistant: Household Labour Supply, Family Time and Subjective Time Pressure in Australia 1997-2006. J Comp Fam Stud. 2009;40(4):547-61.

41. Ng W, Diener E, Raksha A, Harter J. Affluence, feelings of stress, and well-being. Soc Indic Res. 2009;94:257-71. http:// dx.doi.org/10.1007/s11205-008-9422-5.

42. Roxburgh S. Racing through life: The distribution of time pressures by roles and role resources among full-time workers. J Family Econ Issues. 2002;23:121-45. http://dx.doi. org/10.1023/A:1015734516575. 
43. Halrynjo S, Lyng ST. Preferences, constraints or schemas of devotion? Exploring Norwegian mothers' withdrawals from high-commitment careers. Brit J Sociol. 2009;60:321-43. http://dx.doi.org/10.1111/j.1468-4446.2009.01233.x.

44. Australian Institute of Family Studies. The Longitudinal Study of Australian Children Annual Statistical Report 2010; 2011.

45. Strazdins L, Griffin AL, Broom DH, et al. Time scarcity: Another health inequality. Environ Plann A. 2011;43(3):54559. http://dx.doi.org/10.1068/a4360.

46. Floderus B, Hagman M, Aronsson G, Marklund S, Wikman A. Self-Reported Health in Mothers: The Impact of Age, and Socioeconomic Conditions. Women Health. 2008;47(2):63-86. http://dx.doi.org/10.1080/03630240802092308.

47. Baxter J, Chesters J. Perceptions of Work-Family Balance: How Effective are Family-Friendly Policies? Australian J Lab Econ. 2011;14(2):139-51.
48. Ferrer-i-Carbonell A, Frijters P. How important is methodology for the estimates of the determinants of life satisfaction? Econ J. 2004;114(497):641-59. http://dx.doi.org/10.1111/j.14680297.2004.00235.x.

49. Brief AP, Burke MJ, George JM, Robinson BS, Webster J. Should negative affectivity remain an unmeasured variable in the study of job stress? J Appl Psychol. 1988;73(2):167-83. http://dx.doi.org/10.1037/0021-9010.73.2.193.

50. Fisher GG, Matthews RA, Gibbons AM. Developing and investigating the use of single-item measures in organizational research. J Occup Health Psychol. 2016;21(1):3-23. http:// dx.doi.org/10.1037/a0039139.

Received for publication: 23 November 2015 